\title{
The Relationship Between Arterial Elasticity and Metabolic Syndrome Features
}

\author{
Anette S. Fjeldstad, MS, * Cecilie Fjeldstad, MS, * Luke S. Acree, MS, * \\ Kevin J. Nickel, BA, * Polly S. Montgomery, MS, ${ }^{\dagger}$ Philip C. Comp, MD, PhD,,$\$$ \\ Thomas L. Whitsett, MD, " and Andrew W. Gardner, PhD, ${ }^{\dagger}$ \\ Norman and Oklahoma City, OK
}

\begin{abstract}
The purpose of this study was to examine the effects of metabolic syndrome (MS) features on arterial elasticity of the large and small arteries in apparently healthy adults, to examine the effect of clustered features of MS, and to determine which features are most predictive of large and small artery elasticity. The subjects for this study consisted of 126 men and women, age 45 years and older. The subjects rested supine while pulse contour analysis was measured from the radial artery by using an HDI/Pulsewave CR-2000 instrument (Hypertension Diagnostic, Inc) to assess arterial elasticity in the large and small arteries. Medical history was obtained along with body mass index, waist circumference, body surface area, and blood pressure. Large artery elasticity was lower $(p=0.002)$ in subjects with hypertension $(12.7 \pm 4.3 \mathrm{~mL} / \mathrm{mm} \mathrm{Hg} \times 10)$ than in those with normotension $(15.0 \pm 4.2 \mathrm{~mL} / \mathrm{mm} \mathrm{Hg} \times 10$; mean \pm SD), and small artery elasticity was lower $(p=0.001)$ as well $(3.9 \pm 2.3 \mathrm{~mL} / \mathrm{mm} \mathrm{Hg} \times$ 100 vs $5.3 \pm 2.5 \mathrm{~mL} / \mathrm{mm} \mathrm{Hg} \times 100)$. Large artery elasticity was lower $(p=0.02)$ in obese subjects $(12.2 \pm 4.9 \mathrm{~mL} / \mathrm{mm} \mathrm{Hg} \times 10)$ than in nonobese subjects $(14.2 \pm 4.5 \mathrm{~mL} / \mathrm{mm} \mathrm{Hg} \times 10)$, and large artery elasticity was lower $(p=0.04)$ in subjects with abdominal obesity $(12.2 \pm 4.5$ $\mathrm{mL} / \mathrm{mm} \mathrm{Hg} \times 10)$ than in those without $(14.5 \pm 4.8 \mathrm{~mL} / \mathrm{mm} \mathrm{Hg} \times 10)$. Large artery elasticity decreased as the number of features of MS increased $(p<0.01)$. Multiple regression showed that body mass index and the presence of hypertension were predictors of large artery elasticity $\left(R=0.61, R^{2}=0.37, \mathrm{p}=0.003, \mathrm{SEE}=3.60 \mathrm{~mL} / \mathrm{mm} \mathrm{Hg} \times 10\right)$, and hypertension was a predictor of small artery elasticity $\left(R=0.53, R^{2}=0.28, \mathrm{p}=0.001, \mathrm{SEE}=2.12 \mathrm{~mL} / \mathrm{mm} \mathrm{Hg} \times\right.$ $100)$. Hypertension and obesity are the features of MS that are most predictive of impairment in large and small artery elasticity in apparently healthy middle-aged and older adults. Furthermore, impairment in large artery elasticity is more evident in subjects with at least three features of MS.
\end{abstract}

Angiology 58:5-10, 2007

From the *Department of Health and Exercise Science, University of Oklahoma, Norman; and ${ }^{*}$ CMRI Metabolic Research Center and Department of Medicine, Hematology and "Cardiovascular Sections, and ${ }^{\S}$ Department of Veteran Affairs Medical Center, Oklahoma City, OK

This research was supported by grants from the National Institute on Aging (NIA) (R01-AG-16685; AWG), by a University of Oklahoma Research Council grant (AWG), and by the University of Oklahoma Health Sciences Center General Clinical Research Center grant (M01-RR-14467) sponsored by the National Center for Research Resources from the National Institutes of Health Correspondence: Andrew W. Gardner, PhD, CMRI Hobbs-Recknagel Chair, University of Oklahoma Health Sciences Center, 1122 N.E. 13th Street, ORI-W 1400, Oklahoma City, OK 73117

E-mail: andrew-gardner@ouhsc.edu

DOI: 10.1177/0003319706297911

(C)2007 Sage Publications 


\section{Introduction}

Metabolic syndrome (MS) is defined by the Adult Treatment Panel (ATP) III as having three or more of the following criteria: (1) abdominal obesity (waist circumference $>102 \mathrm{~cm}$ in men and $>88 \mathrm{~cm}$ in women), (2) hypertriglyceridemia ( $>150 \mathrm{mg} / \mathrm{dL})$, (3) low HDL cholesterol $(<40 \mathrm{mg} / \mathrm{dL}$ in men and $<50 \mathrm{mg} / \mathrm{dL}$ in women), (4) blood pressure, $130 / 85 \mathrm{~mm} \mathrm{Hg}$ or higher, and (5) fasting glucose of $110 \mathrm{mg} / \mathrm{dL}$ or more. ${ }^{1}$ Having a body mass index (BMI) of $30 \mathrm{~kg} / \mathrm{m}^{2}$ or more is a criterion of MS according to the World Health Organization. ${ }^{1}$ The prevalence of MS is $23.7 \%$ in the adult population, ${ }^{2}$ increasing the risk of coronary artery disease by $70 \% .^{3}$

Arterial elasticity has received growing attention during the last decade because of its association with cardiovascular diseases. ${ }^{4}$ Increased arterial stiffness is associated with increased aortic pulse wave velocity (PWV), an important marker linked to cardiovascular disease. ${ }^{5}$ Increased stiffness of large arteries commonly occurs with advancing age, thereby leading to the development of arteriosclerosis regardless of the presence of coexisting diseases. ${ }^{6}$ In addition, decreased arterial elasticity is associated with hypertension, elevated levels of triglycerides, diabetes, and aging, ${ }^{7}$ and may be an early marker for the development of cardiovascular disease. ${ }^{8}$ Arterial elasticity can be assessed noninvasively with the use of pulse contour analysis (PCA). ${ }^{9}$

Several studies have focused on PCA and various cardiovascular risk factors such as dyslipidemia, ${ }^{8}$ hypertension, ${ }^{8,10,11}$ abnormal glucose and cholesterol levels, ${ }^{8,12}$ and obesity, ${ }^{8}$ all of which are components of MS. Frequently, individuals possess more than one of these risk factors because one risk factor often brings about another. ${ }^{8}$ Few reports to date have directly examined the effects of MS parameters on arterial elasticity in adults, and whether a cluster of these features lead to further impairment of the large and small arteries. Furthermore, it is unknown which of the MS features are most predictive of arterial elasticity.

The purposes of this study were: (1) to determine the effects of MS features on arterial elasticity of the large and small arteries in apparently healthy adults, (2) to examine the effect of having clustered features of MS arterial elasticity, and (3) to determine which features are most predictive of large and small artery elasticity.

\section{Methods}

\section{Subjects}

Recruitment. A total of 126 subjects (59 males and 67 females) having a mean age of 67 years participated in this study. The subjects were recruited by local newspaper advertisements, flyers, and via mass email message to faculty and staff of the University of Oklahoma.

Exclusion criteria. Subjects were excluded if they were younger than 45 years of age, had a history of cardiovascular disease (CVD), or had a history of peripheral arterial disease (PAD). Prior to participating in the study, each subject completed a written informed consent, as approved by the Institutional Review Board at the University of Oklahoma.

\section{Measurements}

Demographic information. Age, sex, race, cardiovascular disease risk factors, and comorbid conditions were obtained during a medical history interview to begin the evaluation. Height was recorded from a stadiometer (SECA Corporation; Columbia, MD) and body weight was recorded from a scale (SECA Corporation), after the subjects removed their shoes. From these measurements, body mass index (BMI) was calculated as follows: weight $(\mathrm{kg}) /$ height $\left(\mathrm{m}^{2}\right)$. Waist circumference was measured with a Gulick measuring tape at the narrowest part of the torso between the ziphoid process and the umbilicus, and hip circumference was measured at the maximal circumference of the buttocks above the gluteal fold to the nearest $0.1 \mathrm{~cm}$. Blood pressure and heart rate were measured concurrently with the large and small arterial elasticity indices by the oscillometric technique.

Pulse contour analysis (PCA). PCA measurements were obtained in the morning following an overnight fast of at least 8 hours and prior to engaging in any strenuous physical activity. Following 10 minutes of supine rest, large artery (C1) and small artery (C2) elasticity indices were obtained from the radial artery by an HDI/ Pulswave $^{\mathrm{TM}}$ CR-2000 Cardiovascular Profiling System (Hypertension Diagnostic, Inc; Eagan, MN). A blood pressure cuff wrapped around the upper left arm and a rigid plastic wrist stabilizer to minimize movement of the right wrist were used for the PCA test. With the right forearm in a 
Table I. Subject characteristics.

\begin{tabular}{lc}
\hline Variable & Value \\
\hline Age (yr) & $67 \pm 10$ \\
Height (cm) & $168.1 \pm 8.8$ \\
Weight (kg) & $30.4 \pm 7.3$ \\
BMI $\left(\mathrm{kg} \cdot \mathrm{m}^{2}\right.$ ) & $96 \pm 14$ \\
Waist circumference (cm) & $109 \pm 14.6$ \\
Hip circumference (cm) & $0.88 \pm 0.1$ \\
Waist-to-hip ratio & $1.9 \pm 0.2$ \\
BSA (m ${ }^{2}$ ) & 47 \\
Gender (\% Male) & 86 \\
Race (\% Caucasian) & 71 \\
Hypertension (\%) & 51 \\
Hyperlipidemia (\%) & 10 \\
Diabetes (\%) & \\
\hline
\end{tabular}

Values are expressed as mean (SD) or as percentages. performed to evaluate arterial elasticity of subjects with normal and abnormal values of each categorized feature of MS, and clustered features of MS. Because arterial elasticity is affected by body size, ${ }^{14}$ the analyses on large and small artery elasticity were performed by adjusting for body surface area. To assess the effect of clustered MS features, subjects were placed in the following three subgroups: (1) those having less than two MS features, (2) those having two features, and (3) those having three or more features. The sample size of this study yielded statistical power estimates of $80 \%$ or greater to detect group differences of 0.5 standard deviations for the large and small artery elasticity measures. Linear stepwise multiple regression was performed to identify the MS features that were predictive of large and small artery elasticity values, adjusted for body surface area.

All values are presented as mean $\pm \mathrm{SD}$, or percentages. Statistical analyses were performed with the SPSS 11.5 software (Chicago, IL). Statistical significance was set at $\mathrm{p}<0.05$.

\section{Results}

supinated position, an Arterial Pulsewave ${ }^{\mathrm{TM}}$ Sensor was placed on the skin directly over the radial artery at the point of the strongest pulse. The sensor was adjusted to the highest relative signal strength, and the $\mathrm{C} 1$ and $\mathrm{C} 2$ measures were obtained during 30 seconds of blood pressure waveform collection. The radial artery sensor measures large artery elasticity by determining the decay in diastolic pressure and it measures small artery elasticity by determining the decay in reflective waves. In addition, other cardiovascular parameters were recorded during this waveform collection, including blood pressure, pulse rate, systemic vascular resistance, and total vascular impedance. Measurements were obtained and averaged over three consecutive 30 -second trials. This noninvasive approach is repeatable during both long-term and short-term observations, ${ }^{9}$ and is reliable regardless of whether the sensor is placed on the right or left arm during the procedure. ${ }^{13}$

\section{Statistical Analysis}

Descriptive statistics were computed for all measurements. Analysis of covariance (ANCOVA) was
Demographic and clinical measures for all 126 subjects are shown in Table I. The subjects were predominantly white $(86 \%)$ and hypertension was the most prevalent MS feature (71\%). Fortytwo subjects possessed one MS feature, 31 subjects possessed two features, and 53 subjects possessed three or more MS features. Table II shows the relationship between MS variables and arterial elasticity indices adjusted for body surface area. Both large artery elasticity $(\mathrm{p}=0.002)$ and small artery elasticity $(\mathrm{p}=0.001)$ were lower in subjects with hypertension than in those with normotension. Large artery elasticity was lower $(\mathrm{p}=0.02)$ in obese subjects than in nonobese subjects, and it was lower $(\mathrm{p}=0.04)$ in subjects with abdominal obesity than in those without. The effect of diabetes on large and small artery elasticity was not examined because the sample consisted of too few diabetics $(n=12)$ to provide stable estimates for statistical analyses.

Table III shows that large artery elasticity was lower in subjects with at least three MS features $(p<0.01)$ compared to those with fewer than three features. Linear stepwise multiple regression showed that the presence of hypertension and BMI were predictors of large artery 
Table II. Categorical features of the metabolic syndrome and large and small arterial elasticity indices.

\begin{tabular}{lcc}
\hline $\begin{array}{l}\text { Metabolic Syndrome } \\
\text { Variables }\end{array}$ & $\begin{array}{c}\text { Large Artery } \\
\text { Elasticity Index } \\
(\mathrm{mL} / \mathrm{mm} \mathrm{Hg} \times 10)\end{array}$ & $\begin{array}{c}\text { Small Artery } \\
\text { Elasticity Index } \\
(\mathrm{mL} / \mathrm{mm} \mathrm{Hg} \times 100)\end{array}$ \\
\hline
\end{tabular}

Hypertension
No $(\mathrm{n}=36)$
$15.0 \pm 4.2$
$5.3 \pm 2.5$
Yes $(\mathrm{n}=90)$
$12.7 \pm 4.3^{\dagger}$
$3.9 \pm 2.3^{\dagger}$

Hyperlipidemia

$\begin{array}{lll}\text { No }(n=62) & 13.5 \pm 4.3 & 4.1 \pm 2.3 \\ \text { Yes }(n=64) & 13.1 \pm 4.6 & 4.4 \pm 2.5\end{array}$

BMI $>30$
No $(\mathrm{n}=70)$
$14.2 \pm 4.5$
$4.2 \pm 2.1$
Yes $(\mathrm{n}=56)$
$12.2 \pm 4.9 *$
$4.4 \pm 2.8$

Abdominal Obesity
No $(\mathrm{n}=61)$
$14.5 \pm 4.8$
$4.3 \pm 2.4$
Yes $(n=65)$
$12.2 \pm 4.5^{\dagger}$
$4.3 \pm 2.5$

Hypertension, systolic blood pressure $\geq 130 \mathrm{~mm} \mathrm{Hg}$ and/or diastolic blood pressure $\geq 85 \mathrm{~mm} \mathrm{Hg}$; hyperlipidemia by self-report; body mass index $>30 \mathrm{~kg} / \mathrm{m}^{2}$; abdominal obesity based on gender-specific waist circumference criteria, men $\geq 102 \mathrm{~cm}$, women $\geq 88 \mathrm{~cm}$. Values are mean (SD) and are adjusted for body surface area.

*Significant difference between groups ( $<<0.05),{ }^{\dagger}(\mathrm{p}<0.01)$.

Table III. The relationship between clustered features of metabolic syndrome variables and arterial elasticity indices.

\begin{tabular}{lcc}
\hline $\begin{array}{l}\text { Number of Clustered } \\
\text { Features }\end{array}$ & $\begin{array}{c}\text { Large Artery } \\
\text { Elasticity Index } \\
(\mathrm{mL} / \mathrm{mm} \mathrm{Hg} \times 10)\end{array}$ & $\begin{array}{c}\text { Small Artery } \\
\text { Elasticity Index } \\
(\mathrm{mL} / \mathrm{mm} \mathrm{Hg} \times 100)\end{array}$ \\
\hline$\leq 1(\mathrm{n}=42)$ & $14.8 \pm 4.6$ & $4.4 \pm 2.2$ \\
$2(\mathrm{n}=31)$ & $14.2 \pm 4.6$ & $4.4 \pm 2.4$ \\
$\geq 3(\mathrm{n}=53)$ & $11.6 \pm 4.7^{* \dagger}$ & $4.1 \pm 2.8$ \\
\hline
\end{tabular}

Values are mean (SD), adjusted for body surface area.

*Significant difference between $\leq 1$ feature and $\geq 3$ features $(p<0.01)$.

${ }^{\dagger}$ Significant difference between 2 features and $\geq 3$ features $(\mathrm{p}<0.01)$. 
elasticity $\left(R=0.61, R^{2}=0.37, \mathrm{p}=0.003\right.$, SEE $=$ $3.6 \mathrm{~mL} / \mathrm{mm} \mathrm{Hg} \times 10)$, and that hypertension was a predictor of small artery elasticity $(R=0.53$, $R^{2}=0.28, \mathrm{p}=0.001, \mathrm{SEE}=2.12 \mathrm{~mL} / \mathrm{mm} \mathrm{Hg} \times$ 100).

\section{Discussion}

This investigation examined the effects of MS features on large and small arterial elasticity in apparently healthy adults. Our findings suggest that large artery elasticity is impaired by hypertension, obesity, and abdominal obesity, and small artery elasticity is reduced by hypertension. Furthermore, large artery elasticity is impaired in subjects with at least three features of MS. The most predictive features of large artery elasticity are hypertension and obesity, whereas hypertension is the only independent predictor of small artery elasticity.

The impairment in large arterial elasticity in hypertensive patients is consistent with observations of increased pulse wave velocity with increased blood pressure in patients with essential hypertension. ${ }^{11}$ Pulse wave velocity, an indicator of arterial elasticity, is considered a marker and predictor of cardiovascular risk in hypertensive patients because it is associated with the development of atherosclerosis. Consequently, the reduced elasticity of the large arteries in the current sample of hypertensive patients suggests that they have up to $28 \%$ higher risk for cardiovascular mortality. ${ }^{10}$ Meaume et $\mathrm{al}^{15}$ concluded that pulse wave velocity is an independent predictor of cardiovascular deaths in subjects above the age of 70 years. The present study extends these observations by demonstrating that small artery elasticity is reduced in hypertensive patients, suggesting that endothelial function is impaired and may mediate the atherosclerotic process. ${ }^{7}$ Small artery elasticity may therefore be a useful marker of early development of arterial dysfunction.

The impairment in large arterial elasticity in obese subjects and in those with abdominal obesity is consistent with previous reports. ${ }^{16,17}$ Maison et $\mathrm{al}^{17}$ reported that BMI was the central feature of the MS in both men and women, while Sutton-Tyrrell et $\mathrm{al}^{18}$ found that higher levels of abdominal fat was associated with greater artery stiffness in healthy older individuals. Wildman et $\mathrm{al}^{19}$ took this a step further and examined the effect of obesity on vascular stiffness in both young and older adults, and found that body fat measures were among the strongest independent predictors of artery stiffness in both young and older adults. Iannuzzi et $\mathrm{al}^{20}$ found an increased stiffness in obese children, proposing weight reduction and risk-factor control in obese children to prevent atherosclerosis and its sequelae later in life. Furthermore, Choi et $\mathrm{al}^{16}$ reported that pulse wave velocity was significantly associated with greater waist circumference. Collectively, these results suggest that obesity and abdominal obesity are important MS features that impair the elasticity of large arteries, thereby leading to increased risk for cardiovascular morbidity ${ }^{21}$ and mortality. ${ }^{21,22}$

This study supports previous investigations that have found clustered features of MS leads to decreased elasticity of large arteries. ${ }^{8}$ Isomaa et $\mathrm{al}^{21}$ found that a cluster of risk factors were associated with an increased risk of coronary heart disease and morbidity, while Bonora et $\mathrm{al}^{23}$ concluded that subjects with MS are at increased risk for both atherosclerosis and coronary heart disease. Kidawa et $\mathrm{al}^{24}$ found a decrease in artery elasticity in subjects with MS, proposing arterial dysfunction in these subjects.

The main limitation of this study is the crosssectional design, which does not establish a cause and effect relationship between arterial elasticity and MS features. Another limitation is that not all MS features were evaluated, as blood samples for glucose and lipid profiles were not obtained. The determination of subjects who had hyperlipidemia was established through a medical history. Finally, subjects who were taking medication for hypertension and hyperlipidemia were permitted to continue their usual drug regimen. However, the measurement of arterial elasticity in a fasted condition in the morning before taking medications should have minimized any effects of medication on arterial elasticity.

In summary, large artery elasticity is impaired by hypertension, obesity, and abdominal obesity, and small artery elasticity is reduced by hypertension. In addition, large artery elasticity is impaired in subjects with at least three features of MS. In conclusion, hypertension and obesity are the features of MS that are most predictive of impairment in large and small artery elasticity in apparently healthy middle-aged and older adults. Furthermore, impairment in large artery elasticity is most evident in subjects with at least three features of MS. 


\section{REFERENCES}

1. Ford ES, Giles WH: A comparison of the prevalence of the metabolic syndrome using two proposed definitions. Diabetes Care 26:575-581, 2003.

2. Ford ES, Giles WH, Dietz WH: Prevalence of metabolic syndrome among US adults. JAMA 287:356359, 2002.

3. Onat A, Ceyhan K, Basar O, et al: Metabolic syndrome: Major impact on coronary risk in a population with low cholesterol levels: A prospective and cross-sectional evaluation. Atherosclerosis 165:285292, 2002.

4. Havlik RJ, Simonsick EM, Sutton-Tyrrell K, et al: Association of physical activity and vascular stiffness in 70-to-79-year-olds: The health ABC study. J Aging Phys Act 11:156-166, 2003.

5. Ogawa O, Onuma T, Kubo S, et al: Brachial-ankle pulse wave velocity and symptomatic cerebral infarction in patients with type 2 diabetes: A cross-sectional study. Cardiovasc Diabetol 2:10, 2003.

6. Millasseau SC, Kelly RP, Ritter JM, et al: Determination of age-related increases in large artery stiffness by digital pulse contour analysis. Clin Sci 103:371377, 2002.

7. Prisant LM, Resnick LM, Hollenberg SM: Arterial elasticity among normotensive subjects and treated and untreated hypertensive subjects. Blood Press Monit 6:233-237, 2001.

8. Nakanishi N, Suzuki K, Tatara K: Clustered features of the metabolic syndrome and the risk for increased aortic pulse wave velocity in middle-aged Japanese men. Angiology 54:551-559, 2003.

9. Prisant LM, Pasi M, Jupin D, et al: Assessment of repeatability and correlates of arterial compliance. Blood Press Monit 7:231-235, 2002.

10. Blacher JR, Asmar S, Djane GM, et al: Aortic pulse wave velocity as a marker of cardiovascular risk in hypertensive patients. Hypertension 33:1111-1117, 1999.

11. Ni Y, Wang H, Hu D, et al: The relationship between pulse wave velocity and pulse pressure in Chinese patients with essential hypertension. Hypertens Res 26:871-874, 2003.

12. Ohnishi H, Sattoh S, Takagi S, et al: Pulse wave velocity as an indicator of atherosclerosis in impaired fasting glucose. Diabetes Care 26:437-440, 2003.

13. Alavi H, Prisant LM, Jupin D, et al: Comparison of arterial elasticity measured in left and right arms using the HDI/PulseWave ${ }^{\mathrm{TM}}$ CR-2000 Research System. Blood Press Monit 7:277-280, 2002.

14. Wildman RP, Farhat GN, Patel AS: Weight change is associated with change in arterial stiffness among healthy young adults. Hypertension 45:187-192, 2005.

15. Meaume S, Benetos A, Henry OF: Aortic pulse wave velocity predicts cardiovascular mortality in subjects $>70$ years of age. Arterioscler Throm Vasc Biol 21:2046-2050, 2001.
16. Choi KM, Lee KW, Seo JA, et al: Relationship between brachial-ankle pulse wave velocity and cardiovascular risk factors of the metabolic syndrome. Diabetes Res Clin Pract 66:57-61, 2004.

17. Maison P, Byrne CD, Hales CN, et al: Do different dimensions of the metabolic syndrome change together over time? Diabetes Care 24:1758-1763, 2001.

18. Sutton-Tyrrell K, Newman A, Simonsick EM, et al: Aortic stiffness is associated with visceral adiposity in older adults enrolled in the study of health, aging, and body composition. Hypertension 38:429-433, 2001.

19. Wildman RP, Mackey RH, Bostom A, et al: Measures of obesity are associated with vascular stiffness in young and older adults. Hypertension 42:468-473, 2003.

20. Iannuzzi A, Licenziati MR, Acampora C, et al: Increased carotid intima-media thickness and stiffness in obese children. Diabetes Care 27:2506-2508, 2004.

21. Isomaa $\mathrm{B}$, Almgren $\mathrm{P}$, Tuomi $\mathrm{T}$, et al: Cardiovascular morbidity and mortality associated with the metabolic syndrome. Diabetes Care 24:683-689, 2001.

22. Katzmarzyk PT, Church TS, Janssen I, et al: Metabolic syndrome, obesity, and mortality. Diabetes Care 28:391-397, 2005.

23. Bonora E, Kiechl S, Willeit J, et al: Carotid atherosclerosis and coronary heart disease in the metabolic syndrome. Diabetes Care 26:1251-1257, 2003.

24. Kidawa M, Krzeminska-Pakula M, Peruga JZ, et al: Arterial dysfunction in syndrome $\mathrm{x}$ : Results of arterial reactivity and pulse wave propagation tests. Heart 89:422-426, 2003. 